\title{
A review of multi-factor capacity expansion models for manufacturing plants: Search for a holistic decision process
}

\begin{abstract}
Investment in capacity expansion remains one of the most critical decisions for a manufacturing organisation with global production facilities. Multiple factors need to be considered making the decision process very complicated. The purpose of this paper is to establish the state-of-the-art in multi-factor models for capacity expansion in manufacturing plants and networks. A three phase research programme is presented consisting of an extensive literature review and a structured assessment of the strengths and weaknesses of the current research. The study found that there is a substantial amount of work on development of mathematical multi-factor models for capacity expansion. Despite that, no single work captures all the different facets of the problem.
\end{abstract}

Keywords: Manufacturing network, capacity expansion, multiple factor, holistic models 


\section{Introduction}

Investment in capacity expansion remains one of the most critical decisions for a manufacturing organisation with global production facilities. In the late 1970s, Wheelwright (1978) put forward the notion that aggregate capacity was one of the five strategic manufacturing decision areas and so a key part of a company's operations strategy. As Rudberg and Olhager (2003) reported, this view is widely supported (e.g. by Porter, 1980; Fine and Hax, 1985; Hill, 1989; Samson, 1991; Miltenburg, 1995; Slack et al., 1995; and Skinner, 1996). The capacity expansion decision can vary in form, for example, it can be in a policy based on an infinite time horizon or a one-off expansion step based on a single period (Luss, 1982). The decision can specify the timing of expansion, the size of expansion, the product impacted and the production location. Similarly, the various factors affecting this decision can include the global manufacturing strategy of the firm, the prevailing and future forecasted market conditions and the competitive strengths of the various factories and locations. The combination of these factors makes each capacity expansion decision in a manufacturing network different and complex and hence no single solution exists.

Since the early 1960s, many quantitative studies of capacity expansion problems have been conducted. Manne (1961) provides the first and simplest models of capacity expansion with deterministic demand, single facility and infinite economic life. His book (Manne, 1967a) provides a description of various capacity expansion problems in which optimal location for each expansion is considered explicitly (Erlenkotter, 1967; Manne, 1967b). By the early 1980s, the capacity expansion literature evolved to include multiple issues and consider multiple facilities in the decision-making process. Luss 
(1982) points out that the typical objective was to minimise the discounted costs associated with the expansion process. Porter (1980), however, argued that the capacity expansion problem is not as simple as just carrying out such analysis based on a few factors. Estimating the factors that influence a capacity expansion is a subtle problem in industry.

Most of the recent work in the area of capacity expansion decision processes has focused on the advancement of computational techniques (Syam, 2000) to solve different aspects of the problem based on different constraints and objectives. Some work has been carried out investigating soft factors (O'Brien and Smith, 1993; Meijboom and Voordijk, 2003) yet no complete process has been put forward. Thus the challenge is to develop a decision process that can capture leading thinking in the area and to expand this to include soft issues in capacity expansion in global manufacturing networks. This paper therefore aims to establish the state of current research in multiple factor models for capacity expansion in manufacturing plants. This is carried out through a structured literature review of the key contributions against factors that are essential to the holistic consideration of the capacity expansion problem.

The paper is structured as follows. Section 2 describes in detail the industrial problem of capacity expansion in global manufacturing networks and leads to the development of a three phase research programme described in Section 3. The first phase identifies the relevant research in this area (Section 4), followed by the development of a comprehensive list of factors and detailed analysis of relevant literature (Section 5). The third phase comprises a structured analysis of the findings of the research (Section 6). This paper concludes with the identification of gaps and opportunities for future research. 


\section{Background}

This section discusses the industrial challenge, defines the term 'multi-factor models for capacity expansion' and explores the reasons and motives for capacity expansion in manufacturing networks. Existing methods and models that can be used to address capacity expansion problems are also introduced in this section.

\subsection{The industrial challenge}

The industrial challenge stems from the discussions with manufacturing companies in Singapore who have multiple plants across the region. The market for their products is increasing rapidly and, with all factories currently producing close to their maximum capacities, there is a need to decide upon the investment (e.g. on facilities, machines, manpower, etc.) for capacity expansion. Such a decision is normally made by considering the discounted costs associated with the expansion for which a number of models are available in the literature. However, it was suggested (by company managements) that soft factors like human resources (availability and skill levels), logistics connectivity and socio-economic factors of the country should also be considered in the decision. Traditionally, the industrial decision makers use the cost minimisation approach and follow it with the soft considerations but this is not considered the best approach by the company management. The management argued that the accuracy of the models based on cost considerations alone is not as much desired by the practitioners as the ability of a model to consider a number of factors. This premise has formed the basis of the work described in this paper. 


\subsection{Multi-factor model for capacity expansion in manufacturing networks}

The definition of 'multi-factor model for capacity expansion in manufacturing networks' is best approached by considering the associated concepts individually. Capacity is defined in a number of ways by different authors. Slack et al. (1995) define capacity of an operation as the maximum level of value-added activity over a period of time. Alternatively, capacity is often referred to as the throughput or output capacity in terms of the number of units produced by a resource in unit time (Buffa, 1983). As a manufacturing network is a set of plants producing similar goods, 'capacity of the manufacturing network' can be considered to be the sum of capacities of the individual plants. Hence, 'capacity expansion in a manufacturing network' implies addition of capacity to the network. Finally, any decision process can be considered to be a 'multifactor model' if it takes into account a variety of factors as inputs and provides a set of decision factors as output.

Figure 1 illustrates a typical multi-factor model for capacity expansion in manufacturing networks. The decision process takes in different costs, demands, investment budget, socio-economic factors and the manufacturing strategy of a company as inputs and generates the amount of capacity to be expanded in each plant, respective production volumes and investment required as outputs.

Insert Figure 1 here

\subsection{Plant configurations in global manufacturing networks}

Global manufacturing networks can take up a variety of configurations. Chakravarty (2005) suggests two extremes. First, a plant in each country serving its local market (Figure 2a) and, second, a single centralised plant which exports to all countries (Figure 2b). Most global manufacturing networks operate somewhere between the above two 
extreme configurations (Figure 2c). For example, Kanter (1995) uses this to explain Gillette's operations. She reported that $70 \%$ of the $\$ 6$ billion annual sales are outside the US through 58 plants in 28 countries serving markets in 200 countries. As production in plants in a manufacturing network reach their maximum capacities, the need to decide upon the investment for capacity expansion also arises. The capacity expansion decision then becomes critical.

Insert Figure 2 here

\subsection{Previous research on capacity expansion in manufacturing plants}

The first studies in capacity changes aimed for an optimal utilisation model of capital (Marris, 1964). These static capacity situations had two basic assumptions. First was that the demand was constant over the life of the plant. The second assumption was that the total capacity is embodied in a single plant. This model was followed by a dynamic capacity model in which the demand increased with time and the future pattern was known with certainty (assumed to be linear in most cases). Manne (1967a) modelled this capacity expansion in a series of heavy process industries in India.

Manne (1967b) followed his previous work with an integer programming formulation for capacity expansion across two facilities. Erlenkotter (1967) developed a dynamic programming formulation of the same problem with fewer restrictions. This was followed by further improvements in later years by himself (Erlenkotter, 1972; Erlenkotter, 1974) and Freidenfelds (1981). The work in this field has since expanded to include a number of different issues.

Dixit (1980) discussed the effect of capacity expansion decision on entry-deterrence in an industry. Using game theoretic models he explained a number of capacity expansion 
scenarios in an industry with multiple players. This concept has since been extended by various authors in the field of Industrial Organisation (Dixit and Pindyck, 1994). Application of these concepts in U.S. firms is discussed by Bulan (2005), however the scope of the above works is limited to capital budgeting decisions and does not take into account any other issue in capacity expansion.

Luss (1982) provides the latest comprehensive review of capacity expansion literature (van Meighem, 2003) and identifies various research issues (Table 1). Since then, important work has been carried out by many researchers including Reeves et. al (1988), Li and Tirupati (1994), Syam (2000), Perrone et. al (2002), Ryan (2004), Chakravarty (1999; 2005) and Bish and Hong (2006). They have all been addressing issues identified by Luss (1982) as well as extending them. The need now is to provide an updated review of this work, so a proper assessment can be made of the current situation.

Insert Table 1 here

\section{Overview of research programme and methodology}

The aim of the research described in this paper is to provide a contemporary review of research in multi-factor models for capacity expansion and so identify opportunities for future work. To achieve this, the following research objectives have been to:

1. Identify literature relevant to the issues of capacity expansion.

2. Form a review of the factors considered as inputs and outputs, along with the underlying assumption and solution methodologies. 
3. Analyse the strengths and weaknesses of the work and identify the opportunities for further research.

These objectives naturally lead to a three-phase research programme. Phase 1 consisted of a structured search through databases to identify relevant literature and to filter the results based on the definition of capacity expansion in manufacturing networks. Phase

2 generated a comprehensive categorisation of factors based on a detailed review of research. Gaps in the work are identified in Phase 3 and subsequently, a SWOT (Strength, Weaknesses, Opportunities and Threats) analysis has been used to structure the investigation. Execution of Phases 1, 2 and 3 are described in detail in Sections 4, 5 and 6 respectively.

\section{Phase 1: Identification of relevant literature}

This first phase of research set out to identify the work done in the area of capacity expansion. This was initially carried out through searches executed in research databases including ABI/INFORM (Proquest, 2005) and Web of Knowledge (ISI, 2005). The keywords used were 'manufacturing', 'network', ‘capacity’, ‘expansion’ and 'global' and their combinations. Searches in ABI/INFORM were focused on scholarly peer-reviewed journals, whereas the Web of Knowledge searches included conference proceedings and articles from magazines. The keyword combinations of ‘manufacturing-capacity-expansion', ‘capacity-global-expansion’ and 'manufacturingglobal-expansion' yielded the most relevant results. Around 100 papers were identified and included in the first cut search results.

The set of papers collated from the above search were further refined by taking into consideration the industrial domain. Papers not relevant to manufacturing, for example 
those from the sectors of telecommunication networks, power networks, utilities and the chemical industry, were eliminated from the set. Relevant papers were then identified through the title, followed by consideration of the abstract. An additional strategy based on citation of important work was adopted at this stage. Important works like those by Manne (1961; 1967a; 1967b) and Luss (1982) were identified and a search of all papers citing them was also carried out.

Relevant literature identified in Phase 1 was in the overall field of capacity expansion in manufacturing plants. There was a need to further refine this set to select the work that proposed multiple factor models rather than to merely address any single issue of the capacity expansion problem. Examples of the latter included research to determine investment times of capacity expansion under uncertainty (Bean and Smith, 1985; Bean et al., 1992; Higle and Corrado, 1992; Dangl, 1999; Ahmed et al., 2003), investment in flexible production technology (Fine and Freund, 1990; Van Meighem, 1998; Netessine et al., 2002), machine replacement (Rajagopalan et al., 1998; Chand et al., 2000) and risk (Callen and Sarath, 1995; Birge, 2000; Borgonovo and Peccati, 2004).Through this process, eleven multi-factor models were identified based upon eleven papers listed in Table 2.

\section{Phase 2: Factor analysis}

The purpose of this phase was to identify the various factors that were put forward as important within the relevant literature. This was carried out in two steps.

\subsection{Determination of factors important for capacity expansion}

The multi-factor models proposed by the authors were considered in terms of inputs, outputs, assumptions and techniques. These were assessed by tabulating the contribution 
of each researcher as presented in Table 2. Once the classification of factors was completed, cross checking was performed to ensure that all factors indirectly considered were taken into account.

\section{Insert Table 2 here}

\subsection{Detailed analysis of factors}

Based on the classification of relevant literature (Table 2), a more detailed review could be carried out to confirm strengths, weaknesses and opportunities for future work. A summary of this review is provided in this section.

Reeves et al. (1988) considers capacity expansion of an industrial firm producing multiple products in several economic regions over a multiple period horizon. They consider market demand, capital costs, labour costs and transportation costs and some products manufactured by some plants are consumed internally by other plants in the manufacturing network. There are maximum limits on transportation capacity, investment in regional facilities, total capital expenditure and intra regional shipments. They also assume that expected net present values of a unit of capital for each combination of region, time period and capacity expansion in existing or new facilities for production of each product, are available. The decision process, aims to maximise return on capital invested and maximise total output of a given product and the total output of existing facilities in a particular region, whilst minimising capital invested in new facilities, along with labour, production and transportation costs. They solve this multi-objective problem using the Interactive Sequential Goal Programming (ISGP) technique proposed by Masud and Hwang (1981). 
Li and Tirupati (1994) examine a multi-product dynamic investment model for making technology selections and expansion decisions over a finite planning horizon in a firm with a single production facility. The environment is characterised by a dynamic growth in market demand. The objective is to determine the minimal cost schedule for capacity additions to meet the product demands, which are known over the planning horizon. They formulate the problem as a mathematical program and develop a two-phase approach using heuristics to solve it.

Rajagopalan (1998) developed a model that unifies the equipment replacement literature, which generally ignores scale economies; and the capacity expansion literature, which ignores replacement of equipment. This model can also be extended to address issues, such as quantity discounts in purchases, alternative technology selection and multiple equipment types.

Syam (2000) looks at capacity expansion in international markets and considers production costs (labour and manufacturing), logistics costs, and present capacity at the different plants. The capacity of the plant can achieve three discrete levels and the demand has an increasing or decreasing trend. Syam (2000) also explores the costbenefit-risk for various expansion scenarios and argues that even when cost premiums are significant, the managers need to weigh them against the potential political benefits and risk factors when making expansion decisions.

Rajagopalan and Swaminathan (2001) argue that inventory management policies have considerable effects on capacity expansion decisions especially in cases where demand is growing rapidly and the firm periodically needs to add machine capacity. They develop a mathematical programming model as an effective solution approach to 
determine the optimal capacity expansion, production and inventory decisions over time. They study the trade-off between using excess capacity to build inventory and hence postpone future capacity acquisition to using the excess capacity to increase changeovers and reduce lot sizes. Their work is motivated by their interactions with a large firm in the consumer products industry.

Hsu (2002) addresses a capacity expansion problem allowing incremental demand to remain unsatisfied by in-house capacity and use temporary capacity such as leasing or outsourcing. Such a decision is preferred especially in the case of a speculative motive e.g. a firm may delay acquisition of certain technology, which is expected to be cheaper in the near future. The objective of his model is to minimise the total acquisition, holding and operating costs associated with all capacity expansion incurred in a multiperiod planning horizon.

Perrone et al. (2002) also examine capacity expansion in the presence of both flexible and dedicated capacity. They model a firm in a market characterised by uncertain demand where product prices are linearly dependent on its demand. The outputs of the model are price and production volume of each product in scenarios where either flexible or dedicated equipment is used. This is an extension to previous works where fully flexible resources are considered (Caulkins and Fine, 1990; Harrison and Van Mieghem, 1999). They also argue that most of the quantitative models deal with specific and focused problems, neglecting the breadth and complexity of the whole capacity expansion problem. They strengthen the aim of this paper by arguing that the development of an integrated and comprehensive decision-support is a path that should be investigated in deep. 
Gaimon and Burgess (2003) describe the primary trade-off in capacity expansion as "the total cost over all expansions is reduced through a small number of large-sized expansions (economies of scale), whereas the costs associated with deviating from demand are reduced through a large number of small-sized expansions”. They study the relationship between the lead time for capacity expansion and the size of the expansion and also investigate the effects of learning from prior design and implementation on this lead time. They show that a lead time reduction generates benefits, which may exceed the cost savings from economies of scale. A firm thus is able to invest optimally in a larger number of smaller-sized expansions.

Ryan (2004) emphasises the risk of capacity shortages during lead time for adding capacity in environments with demand uncertainty and an obligation to provide a specified level of service. She shows that expansion is needed even in the presence of excess capacity to make up for a growing demand. Also in cases of high uncertainty in demand, larger expansion sizes are necessary, but the main impact is still to provoke earlier installations. Even though the domain of the model is not manufacturing industry, the implications of lead time on capacity expansion in a manufacturing network are obvious. Further, Ryan (2004) develops the model using the financial option pricing concept which has been proven by researchers to provide a more accurate evaluation of investment projects with strategic interactions (Miller and Park, 2002). Bulan (2005) provides substantial evidence of the relationship between investment available with a firm for expansion purposes and the uncertainty in its environment using the real options approach. Similar real option approaches for investment decisions related to capacity expansion have been proposed by Feinstein and Lander (2002), Karsak and Ozogul (2002) and Amico et al. (2003). 
Chakravarty (2005) proposes a model to optimise plant investment decisions for capacity expansion while ensuring that the plant investment overhead is optimally absorbed by products produced from that plant. The model considers the effect of labour cost, transportation cost, demand and import tariff on production quantities, investment and overhead absorption pattern. The concept of productivity differences between countries is modelled and the result is a profile of investment allocation to different plants with a fixed total investment budget.

Melo et al. (2005) propose a mathematical modelling framework to address many practical aspects of manufacturing network design simultaneously. These include dynamic planning horizon, distribution, supply of materials, inventory, facility configurations, availability of capital for investments and storage limitations. They address strategic issues of relocation of capacity, capacity additions in present and new facilities and link the issue of capacity expansion to overall supply chain strategy of a firm. Details of their model can be found in Melo et al. (2003).

\section{Phase 3: Analysis and discussion}

The purpose of this phase is to provide a structured appraisal of the results from Phase 2.

\subsection{Strengths of current research}

There are eleven papers (see Table 2) which were identified as relevant work that addresses multiple factors. Collectively, they comprehensively consider almost all the current issues foreseen in the capacity expansion problem. Four factors appear to be the most important ones as most of the authors considered them as inputs to their models. 
First, product demand was a factor considered by all the authors in one form or another. Chakravarty (2005) incorporated demand as a function of price, based on the concept of demand curves. Rajagopalan and Swaminathan (2001), Hsu (2002), and Gaimon and Burgess (2003) consider unsatisfied (residual) demand as an input whereas all other authors considered overall demand as an input. Rajagopalan (1998), Perrone et al. (2002) and Ryan (2004) also consider uncertainty in the product demand.

Second factor considered important by nine authors is the cost of investment for the required capacity expansion. Reeves (1988) considered expected net present value as an input whereas Hsu (2002) incorporated the capital requirement per unit of output as an input. Except for Syam (2000) and Ryan (2004), all other authors used a standard investment cost function. Rajagopalan (1998) also considers the cost of replacement of existing resources and exhibits how the capacity expansion model can be extended to include concepts of alternative technologies, multiple demand types and quantity discounts.

Thirdly, all authors considered production costs in their models. These costs are categorised as labour, production and transportation costs. Perrone et al. (2002), Chakravarty (2005) and Melo et al. (2005) explicitly consider consider variable cost of production whereas four other authors consider this variable cost indirectly. Most authors consider operating cost function based on a dedicated technology barring Reeves et al. (1988), Li and Tirupati (1994) and Perrone et al. (2002) who include operating cost functions for both dedicated and flexible technologies. Finally, initial capacity is a factor identified as important by the analysis of Table 2. Nine out of eleven of the authors considered it as an input with Li and Tirupati (1994) considering both dedicated and flexible capacity. 
With regards to the techniques used by the authors, seven out of the eleven authors employed some form of mathematical programming. They rigorously developed best solution approaches for the proposed models and thus provided close to optimal results. Perrone et al. (2002), Gaimon and Burgess (2003), Ryan (2004) and Chakravarty (2005) used theoretical modelling techniques to solve the capacity expansion problem with Ryan (2004) including the concepts of financial option pricing in her model. Some work also enhanced the quality of decision support provided by integrating the detailed risk analysis (Syam, 2000) and the sensitivity analysis (Chakravarty, 2005).

In summary, four factors are considered important by almost all the authors. These are product demand, cost of investment, production costs and initial capacity. Most of the authors have also developed comprehensive solution techniques. The techniques are rigorous in nature and are primarily mathematical models which provide close to optimal results. Some authors have enhanced the quality of decision by additional techniques of risk diversification and sensitivity analysis.

\subsection{Weaknesses of current research}

The primary shortcoming of the current state of literature is the lack of any comprehensive multi-factor model based on all the inputs identified. Work by Reeves (1988), Chakravarty (2005) and Melo et al. (2005) are closest to being holistic models as they consider the maximum number of identified factors as input to their multi-factor models.

Economic factors like market size in the country, currency exchange rates and local taxes are incorporated primarily by Chakravarty (2005), who also includes the concept of overhead allocation to individual factories based on their share of the investment 
budget. Syam (2000) incorporates risk diversification in his model whereas Hsu (2002), and Gaimon and Burgess (2003) take into account penalty from capacity shortages.

Only Gaimon and Burgess (2003) and Ryan (2004) take into account lead time for capacity expansion and the effect of learning on capacity expansion. There are however a number of papers discussing the effect of each of the above in isolation. These works however did not qualify as multi-factor models.

Similarly, factors like production efficiency which can inherently capture effects of worker skills and quality of labour are only considered by Reeves et al. (1988) and Rajagopalan and Swaminathan (2001). Accounting policies, investment budgets and other costs like capacity holding and replacement costs are also not considered by most authors. There is thus no single contribution which incorporates all the identified input factors of the capacity expansion problem.

Further, the list of factors although extensive appears incomplete. During the execution of Phase 1, some literature on capacity expansion suggested factors, which are not visible in any of the multi-factor models. Gutenberg (1992) provides an industrial view of investment for capacity expansion based on a questionnaire survey of the German industry and identified, in decreasing order of importance, factors such as expectation of favourable markets, bottleneck elimination in plants, improvement in running costs, market share threatened, tax concessions and fearing a further increase in capital goods. Olhager, Rudberg and Wikner (2001) research the link between manufacturing strategy and capacity expansion decisions, however, none of the identified multi-factor models consider it. 
An additional weakness is that the solution strategy adopted by most authors is almost exclusively mathematical, the emphasis is on costs and the exercise revolves around minimising the discounted costs or maximising the returns on investment. There is a lack of processes that use a combination of decision techniques to yielding a more expansive analysis of the problem. Similarly, none of the work identified the decision makers (personnel from the organisation) who need to be involved, or provided information about the time guidelines required for all steps of the decision process, for example, data identification, gathering and analysis. These are crucial for the implementation of any proposed decision process in the industry.

Finally, there is an absence of industrial case studies which reflect the efficacy of such models in industry. Although Ferdows (1997) provides some industrial examples of capacity expansion based on the concept of strategic roles of factories, and Kim and Lee (2001) discuss capacity expansion strategies based on lessons from Hyundai and Daewoo, their models however are focused more on the strategic level and lack details for implementation. An industrial case of capacity expansion in wafer fabrication industry is presented by Nazzal, Mollaghasemi and Anderson (2006). They provide a complete decision making process including simulation modelling, design of experiments, statistical analysis and economic justification. However, the input to the model is cost of buying equipment and the output is net cash flow derived from change in cycle times.

In summary therefore, there are a number of weaknesses in the current literature. First, there is no model which is holistic enough to handle all the factors deemed important for capacity expansion. Second, there is no description of the sources of data used by 
the models from the perspective of the host company. Finally, implementation studies are also lacking.

\subsection{Opportunities from current research}

The identification of weaknesses of the work provides an important starting point for the opportunities of future work in this area. The first opportunity lies in ratifying the list of factors deemed important for capacity expansion as developed from the literature. This ratification needs to come from the decision makers in industry and can be carried out, for example, by conducting semi-structured interviews. Discussion of qualitative factors like political advantages and manufacturing strategies also need to be conducted during this ratification exercise. Relative importance of various factors, from an industrial perspective, will be an important objective of this exercise.

Another opportunity identified includes the development of a truly holistic decision process for capacity expansion in manufacturing networks. The comprehensive list of factors ratified by the industry can form the industrial specification of such a holistic decision process. The process can derive solution strategies from the available literature and rely on multiple techniques to provide a more complete analysis of the capacity expansion problem.

Finally, the opportunity to conduct comprehensive industrial case studies needs to be acted upon. Testing of the proposed holistic process by the practitioners, and developing an implementation path for the industry are the two main objectives for the case studies. The case studies need to be conducted at different firms to test both the applicability and robustness of any capacity expansion decision making process which claims to be holistic in nature. 


\subsection{Threats from/of current research}

It was observed that there is also no work based on industrial data comparing the different factors and developing a reference list based on importance. There are studies carried out in the related field of facility location (MacCarthy and Atthirawong, 2003; Bhutta, 2004) but results cannot be directly applied to capacity expansion. The work seems to be suffering from the limitation of taking into account quantitative factors like costs, and then applying the softer socio-economic factors on the decisions derived from the quantitative analysis (MacCormack et al., 1994). The threat arises where soft factors supersede the quantitative factors. Taking a stronger stance on this issue, there is no evidence that the entire body of work is still industrially relevant.

\subsection{Summary of analysis}

This analysis is shown in Figure 3. It can be seen that the current condition of literature in this area has a number of weaknesses which open doors to further research. The main focus of future research should thus be in the development of holistic models and the embedding of those models in a decision framework with focus on the users. Industrial case studies will also help strengthen the case for relevance of the work and its utility to the decision-makers in industry.

Insert Figure 3 here

\section{Concluding remarks}

The aim of this paper was to establish the current state of research in multi-factor models for capacity expansion and develop a set of specifications on which any holistic and comprehensive model can be created. The capacity expansion problem has been described and a three stage research programme executed. This included a systematic 
search in the literature followed by a refinement of the search criteria. A list of factors considered by academia has been collated and then contrasted. The current state of literature was then reviewed and a SWOT analysis was used to provide a structured summary of the results.

Although substantial work has been carried out in the development of solution techniques, no model has addressed all the factors considered important to the capacity expansion decision process. The development of a holistic model that is capable of tackling the same problem has been identified as an important research opportunity.

Future research including ratification of the comprehensive list of factors by industry, development of a holistic decision process based on the identified factors and industrial case studies which demonstrate both the efficacy and the short comings of such a process is planned by the authors in the near future. 


\section{References}

Ahmed, S., King, A.J., Parija, G., 2003. A multi-stage stochastic integer programming approach for capacity expansion under uncertainty. Journal of Global Optimisation 26, 3-24.

Amico, M., Pasek, Z. J., Asl, F., Perrone, G. A new methodology to evaluate the real options of an investment using binomial trees and Monte Carlo simulation. Proceeding of the Winter Simulation Conference, New Orleans, USA, 7 - 10 December, 2003, pp. 351-359.

Bean, J.C., Higle, J.L., Smith, R.L., 1992. Capacity expansion under stochastic demand. Operations Research 40 (2), 210-216.

Bean, J.C., Smith, R.L. 1985. Optimal capacity expansion over an infinite horizon. Management Science 31 (12), 1523-1532.

Bhutta, K.S., 2004. International facility location decisions: a review of the modelling literature. International Journal of Integrated Supply Management 1 (1), 33-50.

Birge, J.R., 2000. Option Methods for Incorporating Risk into Linear Capacity Planning Models. Manufacturing \& Service Operations Management 2 (1), 19-31.

Bish, E. K., Hong, S. J., 2006. Coordinating the resource investment decision for a two market, price-setting firm. International Journal of Production Economics 101, 6388.

Borgonovo, E., Peccati, L., 2004. Sensitivity analysis in investment project evaluation. International Journal of Production Economics 90, 17-25. 
Buffa, E. S., 1983. Modern Production/operations Management. New York, Wiley.

Bulan, Laarni T., 2005. Real options, irreversible investment and firm uncertainty: New evidence from U. S. firms. Review of Financial Economics 14, 255-279.

Callen, J.L., Sarath, B., 1995. Risk aversion, generalized correlation and investment in manufacturing capacities. Journal of Operations Management 12 (3-4), 225-237.

Caulkins, J. P., Fine, C. H., 1990. Seasonal inventories and the use of product-flexible manufacturing technology. Annals of Operations Research 26, 351-375.

Chakravarty, A.K., 1999. Profit margin, process improvement and capacity decisions in global manufacturing. International Journal of Production Research 37 (18), 42354257.

Chakravarty, A.K., 2005. Global plant capacity and product allocation with pricing decisions. European Journal of Operational Research 165, 157-181.

Chand, S., McClurg, T., Ward, J., 2000. A model for parallel machine replacement with capacity expansion. European Journal of Operational Research 121, 519-531.

Dangl, T., 1999. Investment and capacity choice under uncertain demand. European Journal of Operational Research 117, 415-428.

Dixit, A., 1980. The role of investment in entry-deterrence. The Economic Journal 90 (March), 95-106.

Dixit, A., Pindyck, R., 1994. Investment under uncertainty. Prineton, NJ, Princeton University Press. 
Erlenkotter, D., 1967, Two Producing Areas - Dynamic Programming Solutions, in A.S. Manne, ed., Investments for Capacity Expansion: Size, Location and Timephasing. Cambridge, MA, MIT Press, 210-227.

Erlenkotter, D., 1972. Economic Integration and Dynamic Location Planning. Swedish Journal of Economics 74, 8-18.

Erlenkotter, D., 1974. Dynamic Programming Approach to Capacity Expansion with Specialisation. Management Science 21, 360-363.

Feinstein, S. P., Lander, D. M., 2002. A better understanding of why NPV undervalues managerial flexibility. The Engineering Economist 47, 418-435.

Ferdows, K., 1997. Making the Most of Foreign Factories. Harvard Business Review March-April, 73-88.

Fine, C.H., Freund, R.M., 1990. Optimal investment in product-flexible manufacturing capacity. Management Science 36(4), 449-466.

Fine, C.H., Hax, A.C., 1985. Manufacturing strategy: A methodology and an illustration. Interfaces 15 (6), 28-46.

Freidenfelds, J., 1981. Near optimal Solution of a Two-Type Capacity Expansion Problem. Computers \& Operations Research 8, 221-239.

Gaimon, C., Burgess, R.H., 2003. Analysis of the lead time and learning for capacity expansion. Production and Operations Management 12 (1), 128-140.

Gutenberg, E., 1992. Investment Policy in Industrial Enterprises. Management International Review 32(1), 17-28. 
Harrison, J. M., Van Mieghem, J. A., 1999. Multi-resource investment strategies: operational hedging under demand uncertainty. European Journal of Operational Research 113, 17-29.

Higle, J.L., Corrado, C.J., 1992. Economic investment times for capacity expansion problems. European Journal of Operational Research 59, 288-293.

Hill, T., 1989. Manufacturing Startegy: Text and Cases. Hampshire, Palgrave.

Hsu, V. N., 2002. Dynamic capacity expansion problem with deferred expansion and age-dependent shortage cost. Manufacturing \& Service Operations Management 4 (1), 44-54.

ISI, 2005. Web of Knowledge: Web of Science. http://wok.mimas.ac.uk/

Kanter, R., 1995. The new business cosmopolitans. Strategy and Business. Fall, 66-77.

Karsak, E. E., Ozogul, C. O., 2002. An options approach to valuing expansion flexibility in flexible manufacturing. The Engineering Economist 47, 169-193.

Kim, B., Lee, Y., 2001. Global capacity expansion strategies: Lessons learnt from two Korean carmakers. Long Range Planning 34, 309-333.

Li, S., Tirupati, D., 1994. Dynamic capacity expansion problem with multiple products: Techology selection and timing of capacity expansion. Operations Research 42 (5), 958-976.

Luss, H., 1982. Operations Research and Capacity Expansion Problems: A Survey. Operations Research 30 (5), 907-947. 
MacCarthy, B.L., Atthirawong, W., 2003. Factors affecting location decisions in international operations - a Delphi study. International Journal of Operations \& Production Management 23 (7), 794-818.

MacCormack, A.D., Newman III, L.J., Rosenfield, D.B., 1994. The New Dynamics of Global Manufacturing Site Location. Sloan Management Review 35 (4), 69-80.

Manne, A.S., 1961. Capacity Expansion and Probabilistic Growth. Econometrica 29, 632-649.

Manne, A.S., 1967(a). Investments for Capacity Expansion: Size, Location and TimePhasing, MIT Press, Cambridge, MA, MIT Press.

Manne, A.S., 1967(b), Two Producing Areas - Constant Cycle Time Policies, in A.S. Manne, ed., Investments for Capacity Expansion: Size, Location and Timephasing. Cambridge, MA, MIT Press, 193-209.

Marris, R., 1964. The Economics of Capital Utilisation: A Report on Multiple Shift Work. Cambridge University Press.

Masud, A.S., Hwang, C.L., 1981. Interactive sequential goal programming. Journal of Operational Research Society 32, 391-400.

Meijboom, B., Voordijk, H., 2003. International operations and location decisions: a firm level approach. Tijdschrift voor economische en sociale geografie 94 (4), 463-476.

Melo, M.T., Nickel, S., da Gama, F.S., 2003. Large-scale models for dynamic multicommodity capacitated facility location. Fraunhofer Institut Techno- und Wirtschaftsmathematik. 58. www.itwm.fraunhofer.de 
Melo, M.T., Nickel, S., da Gama, F.S., 2005. Dynamic multi-commodity capacitated facility location: a mathematical modeling framework for strategic supply chain planning. Computers \& Operations Research 33, 181-208.

Miller, T. L., Park, C. S., 2002. Decision making under uncertainty- Real options to the rescue? The Engineering Economist 47, 105-150.

Miltenburg, J., 1995. Manufacturing strategy: How to formulate and implement a winning plan. Portland, OR, Productivity Press.

Nazzal, D., Mollaghasemi, M., Anderson, D., 2006. A simulation-based evaluation of the cost of cycle time reduction in Agere Systems wafer fabrication facility - a case study. International Journal of Production Economics 100, 300-313.

Netessine, S., Dobson, G., Shumsky, R.A. 2002. Flexible service capacity: Optimal investment and the impact of demand correlation. Operations Research 50 (2), 375-388.

O’Brien, C., Smith, S.J.E., 1993. Design of the decision process for strategic investment in advanced manufacturing systems. International Journal of Production Economics 30-31, 309-322.

Olhager, J., Rudberg, M., Wikner, J., 2001. Long-term capacity management: Linking the perspectives from manufacturing strategy and sales and operations planning. International Journal of Production Economics 69, 215-225.

Perrone, G, Amico, M., Lo Nigro, G., La Diega, S.N., 2002. Long term capacity decisions in uncertain markets for advanced manufacturing systems incorporating scope economies. European Journal of Operational Research 143 (1), 125-137. 
Porter, M.E., 1980. Competitive Strategy. New York, NY, Free Press.

Proquest, 2005. ABI/INFORM. http://www.umi.com/products/pt-product-ABI.shtml

Rajagopalan, S., Singh, M., Morton, T., 1998. Capacity expansion and replacement in growing markets with uncertain technology breakthroughs. Management Science 44, 12-30.

Rajagopalan, S., 1998. Capacity expansion and equipment replacement: A unified approach. Operations Research 46 (6), 846-857.

Rajagopalan, S., Swaminathan, J.M., 2001. A coordinated production planning model with capacity expansion and inventory management. Management Science 47 (11), 1562-1580.

Reeves, G.R., Lawrence, K.D., Lawrence, S.M., Gonzalez, J.J., 1988. A Multiple Criteria Approach to Aggregate Industrial Capacity Expansion. Computers and Operations Research 15 (4), 333-339.

Rudberg, M., Olhager, J., 2003. Manufacturing networks and supply chains: an operations strategy perspective. Omega 31, 29-39.

Ryan, S.M., 2004. Capacity expansion for random exponential demand growth with lead times. Management Science 50 (6), 740-748.

Samson, D., 1991. Manufacturing and operations strategy. Sydney, Prentice-Hall.

Skinner, W., 1996. Three yards and a cloud of dust: Industrial management at century end. Production and Operations Management 5 (1), 15-24. 
Slack, N., Chambers, S., Harland, C., Harrison, A., Johnson, R., 1995. Operations Management, Pitman Publishing.

Syam, S.S., 2000. Multiperiod Capacity Expansion in Globally Dispersed Regions. Decision Sciences 31 (1), 173-195.

Van Meighem, J.A., 1998. Investment strategies for flexible resources. Management Science 44 (8), 1071-1078.

Van Meighem, J.A., 2003. Capacity Management, Investment, and Hedging: Review and Recent Developments. Manufacturing \& Service Operations Management 5 (4), 269-302.

Wheelwright, S.C., 1978. Reflecting Corporate Strategy in Manufacturing Decisions. Business Horizons 21 (February), 57-66. 


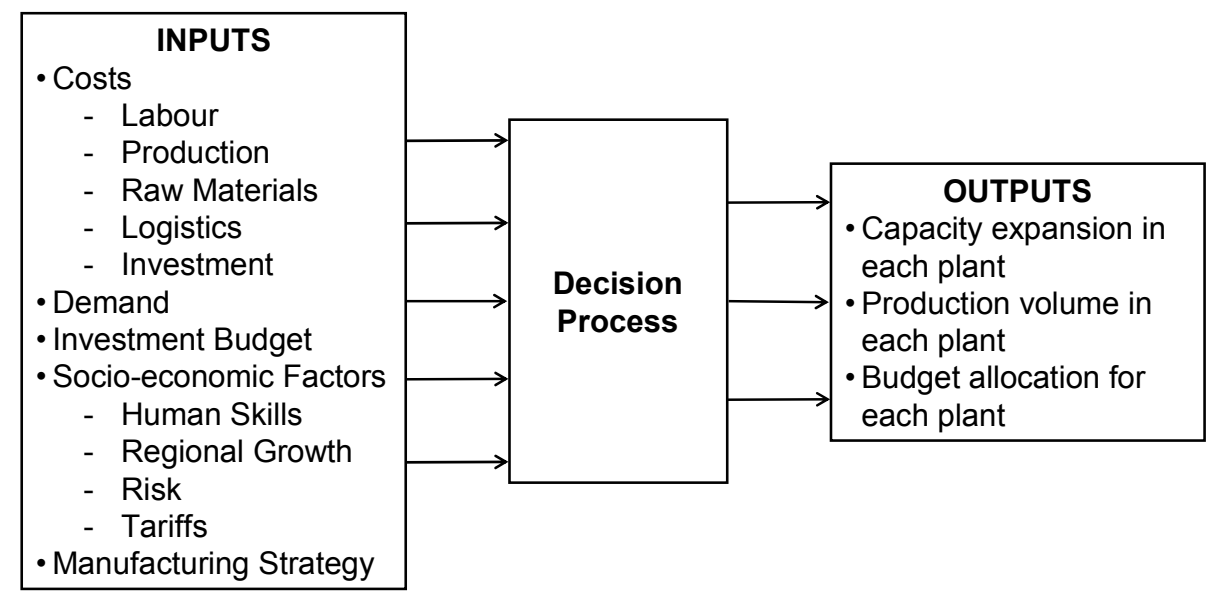

Figure 1 - Example of inputs and outputs for a multi-factor model for capacity expansion 

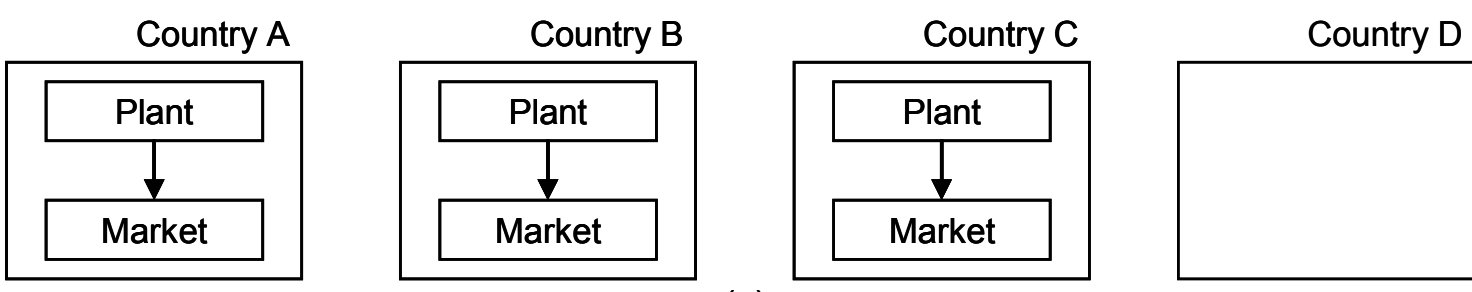

(a)

Plant producing for local market
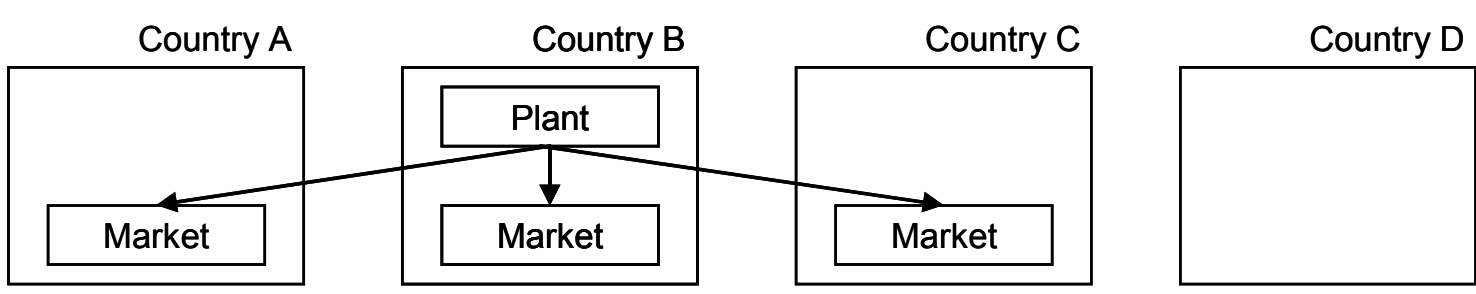

(b)

Centralised plant producing for global market
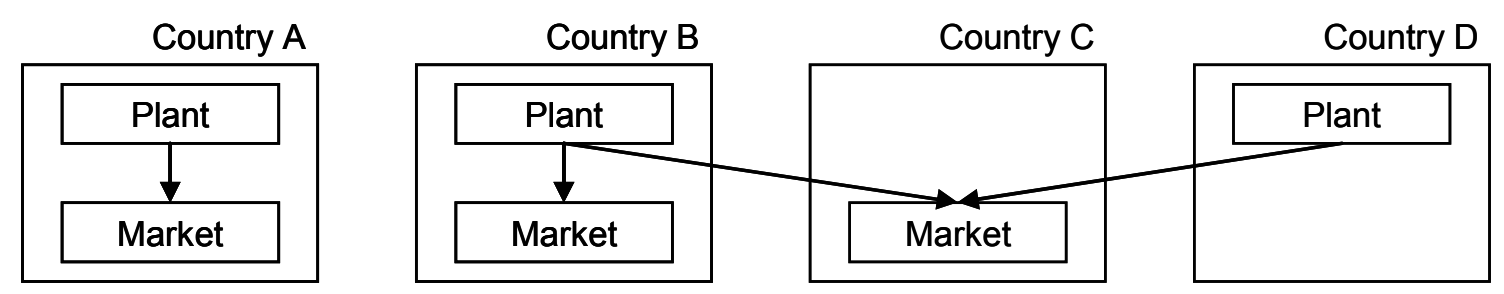

(c)

Optimal plant configuration

Figure 2 - Plant configurations for global manufacturing networks (adapted from Chakravarty, 2005) 


\begin{tabular}{|c|c|}
\hline $\begin{array}{l}\text { Strengths } \\
\text { - Four factors considered important - } \\
\text { product demand, cost of investment, } \\
\text { production costs and initial capacity. } \\
\text { - Solution techniques are rigorous. Solution } \\
\text { techniques which provide close to optimal } \\
\text { results are also developed. } \\
\text { - Quality of decision is enhanced by } \\
\text { additional techniques of risk diversification } \\
\text { and sensitivity analysis. }\end{array}$ & $\begin{array}{l}\text { Weaknesses } \\
\text { - No model holistic enough to handle all the } \\
\text { factors deemed important for capacity } \\
\text { expansion. } \\
\text { - The list of factors is extensive but } \\
\text { incomplete. } \\
\text { - No description of the sources of data or } \\
\text { involvement of company personnel. } \\
\text { - Guidelines for industrial adoption absent. } \\
\text { No case studies that will enable a } \\
\text { decision maker to adopt such models. }\end{array}$ \\
\hline $\begin{array}{l}\text { Opportunities } \\
\text { - Development of a holistic model for } \\
\text { capacity expansion based on the list of } \\
\text { factors identified in the study } \\
\text { - Development of an implementation path } \\
\text { to facilitate adoption of above model to } \\
\text { industry } \\
\text { - Conduct a case study based on the above } \\
\text { process }\end{array}$ & $\begin{array}{l}\text { Threats } \\
\text { - Research moving away from the industry } \\
\text { and users } \\
\text { - Work not embedded in decision sciences } \\
\text { - Industrial relevance needs to be } \\
\text { established with case-studies }\end{array}$ \\
\hline
\end{tabular}

Figure 3 - A summary of the current condition of literature in the field of multifactor capacity expansion models for the manufacturing industry 
Table 1 - Issues in the Capacity Expansion Problem (adapted from Luss, 1982)

\begin{tabular}{|c|c|}
\hline Issue & Features \\
\hline \multirow{2}{*}{ Size } & $\begin{array}{l}\text { Continuous (with fixed/ variable/ lumpy expansion } \\
\text { sizes) }\end{array}$ \\
\hline & Finite (fixed number of expansion sizes and duration) \\
\hline \multirow{2}{*}{ Time } & Dynamic Capacity Expansion (expansion policy) \\
\hline & Single Period Problem \\
\hline \multirow{3}{*}{ Location (including Type) } & Single Facility \\
\hline & Two Facility \\
\hline & Multiple Facility \\
\hline \multirow{4}{*}{ Cost Functions } & Power Cost Function \\
\hline & Fixed Charge \\
\hline & Combination \\
\hline & Piecewise Concave (Technology-based Expansion) \\
\hline \multirow{3}{*}{ Demand Function } & Linear: $\mu+\delta t$ \\
\hline & Exponential: $\mu \exp (\delta t)$ \\
\hline & Decreasing exponential with saturation: $\beta(1-\exp (\delta t))$ \\
\hline \multirow{3}{*}{ Deferring Expansion } & Capacity Shortages \\
\hline & Inventory Build-up \\
\hline & Temporary "importing" capacity (Outsourcing) \\
\hline \multirow{4}{*}{ Costs } & Congestion cost \\
\hline & Holding cost \\
\hline & Operating cost as function of demand \\
\hline & Operating cost as function of technology and age \\
\hline \multirow{4}{*}{ Decision Maker Constraints } & Budgetary Constraints \\
\hline & Corporate Policies \\
\hline & Upper Bounds on Expansion Sizes \\
\hline & Excess Capacity \\
\hline \multirow{3}{*}{$\begin{array}{l}\text { Special Issues with } \\
\text { Multifacility }\end{array}$} & Multilocation - Same Country / Area \\
\hline & Multilocation - Global \\
\hline & Multitype (Multiple Products) \\
\hline \multirow{2}{*}{ Capacity Modification } & Capacity Conversion \\
\hline & Replacement \\
\hline
\end{tabular}


Table 2 - Contrasting the work on holistic models for capacity expansion

\begin{tabular}{|c|c|c|c|c|c|c|c|c|c|c|c|}
\hline & \multicolumn{11}{|c|}{ AUTHORS } \\
\hline ASSIFICATION FACT & 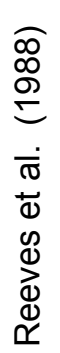 & 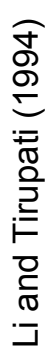 & 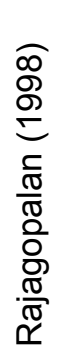 & 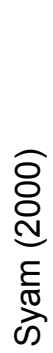 & 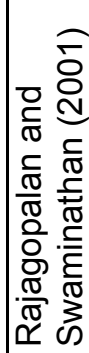 & 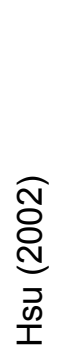 & 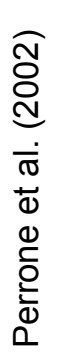 & 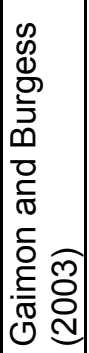 & 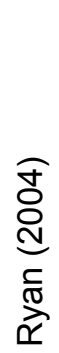 & 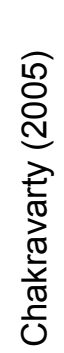 & 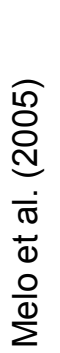 \\
\hline
\end{tabular}

\begin{tabular}{|l} 
Inputs \\
\hline Product demand \\
Overall demand \\
Unsatisfied demand \\
Demand uncertainty \\
Demand function \\
Cost of investment \\
Investment cost function \\
Cost for per unit of capacity \\
Capacity replacement cost \\
Capital requirement per unit output in \\
new facilities \\
Production costs \\
Unit costs of producing goods \\
Annualised per unit labour costs \\
Annualised per unit production costs \\
Annualised per unit transportation costs \\
Variable cost \\
Operating cost function (dedicated \\
technology) \\
Operating cost function (flexible \\
technology) \\
Initial capacity \\
Initial dedicated capacity \\
Initial flexible capacity \\
Market / Economic factors \\
Diversification needed \\
Market size in the country \\
Local taxes \\
Currency exchange rates \\
Capacity shortage penalty (demand \\
unsatisfied) \\
Lead time and learning \\
Lead time for capacity expansion \\
Cost reduction due to learning in the \\
organisation \\
Lead time reduction due to learning \\
\end{tabular}

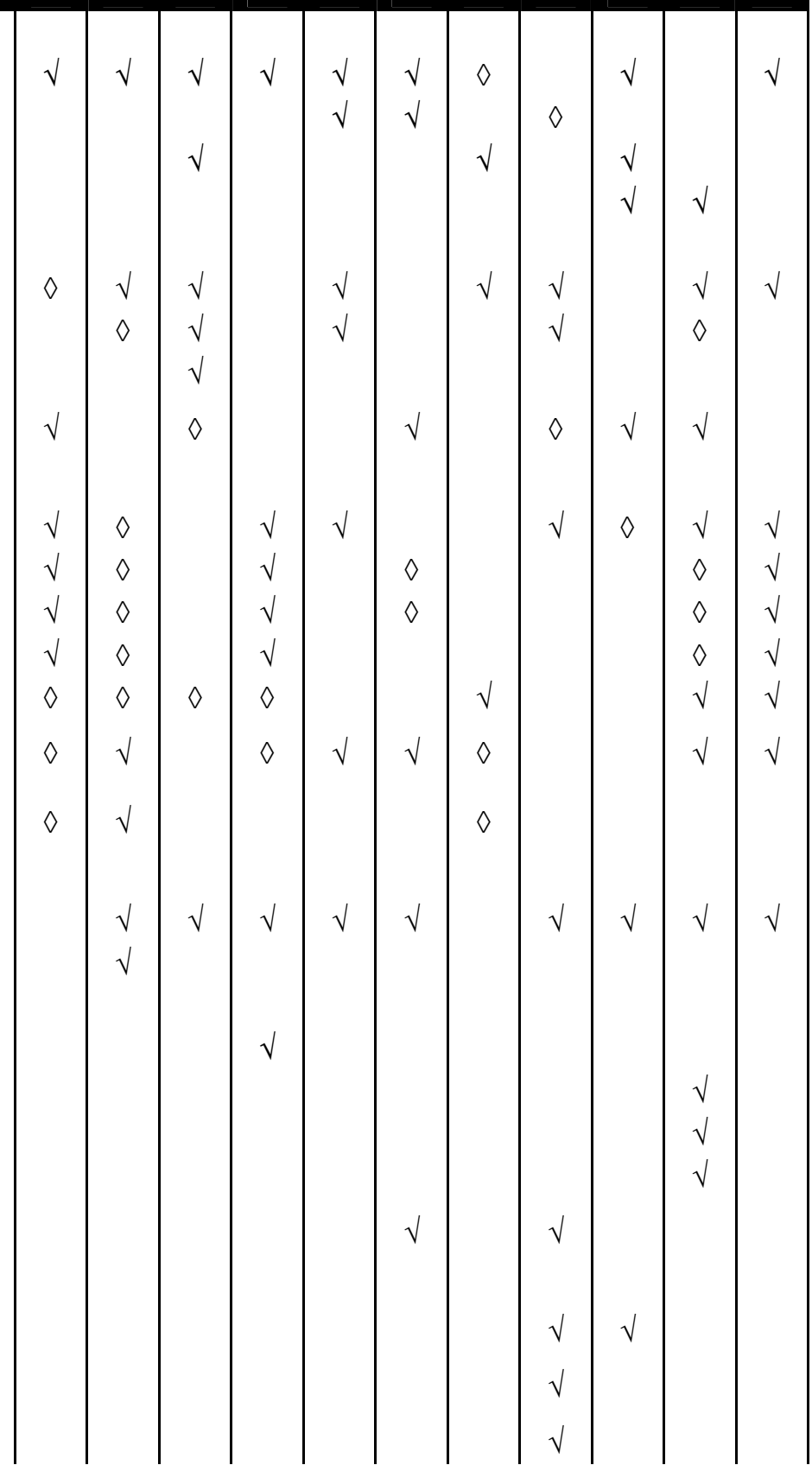


Table 2 - Contrasting the work on holistic models for capacity expansion (cont)

\begin{tabular}{|l} 
Production efficiency \\
Technical coefficient modelling input- \\
output relationship \\
Unit processing time (production) \\
Accounting policies \\
Expected net present values for per unit \\
of capital \\
Allocation of plant overheads \\
Investment budget \\
Regional expansion budget \\
Global expansion budget \\
Other costs \\
Capacity holding costs \\
Capacity relocation costs
\end{tabular}

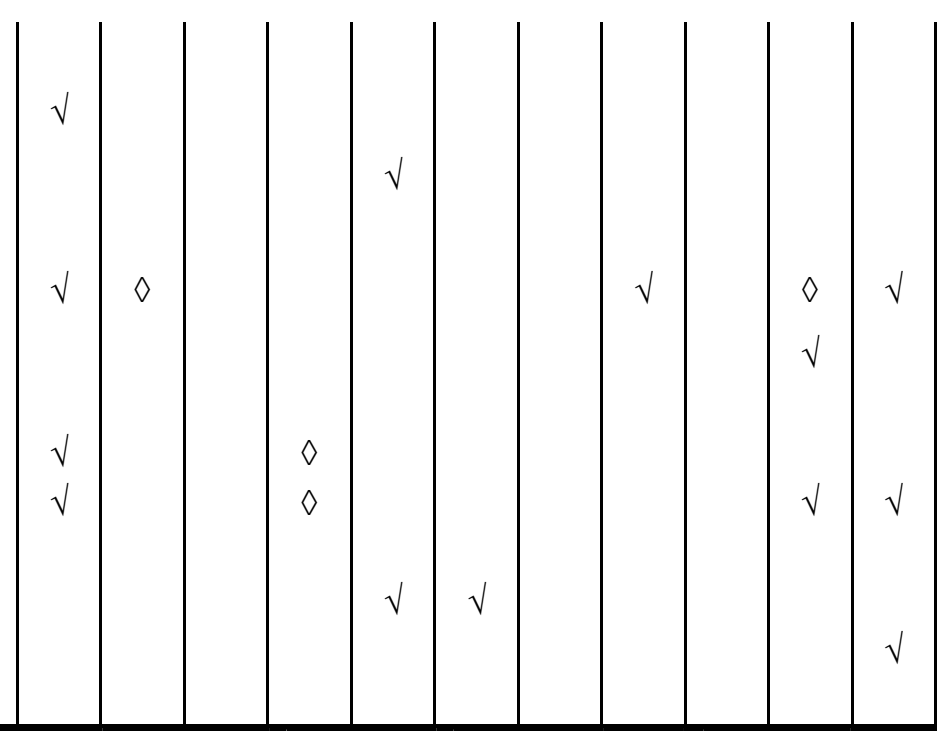

\section{Outputs}

Production volume (dedicated technology)

Production volume (flexible technology)

Price of product produced (dedicated

technology)

Price of product produced (flexible technology)

Timing of capacity expansion

Production quantity in different plants

Return on capital invested

Total capital invested in new facilities

Total labour, production and transport costs

Amount of capacity addition (dedicated \&

flexible)

Total discounted costs over planning horizon

Inventory carrying costs

Inventory planning policies

Capacity shifted from old facility to new

Capital invested in each plant

\section{Assumptions}

Multiple plants producing multiple products

Single plant producing multiple products

Machine replacement permitted

Quantity discounts

Service level to customer to be maintained

Risk of capacity shortages considered

Deferred capacity expansion (leasing/

outsourcing)

Capacity takes certain leadtime to come online Input-output relationship between plants

Limited transport capacity

Limited regional budget

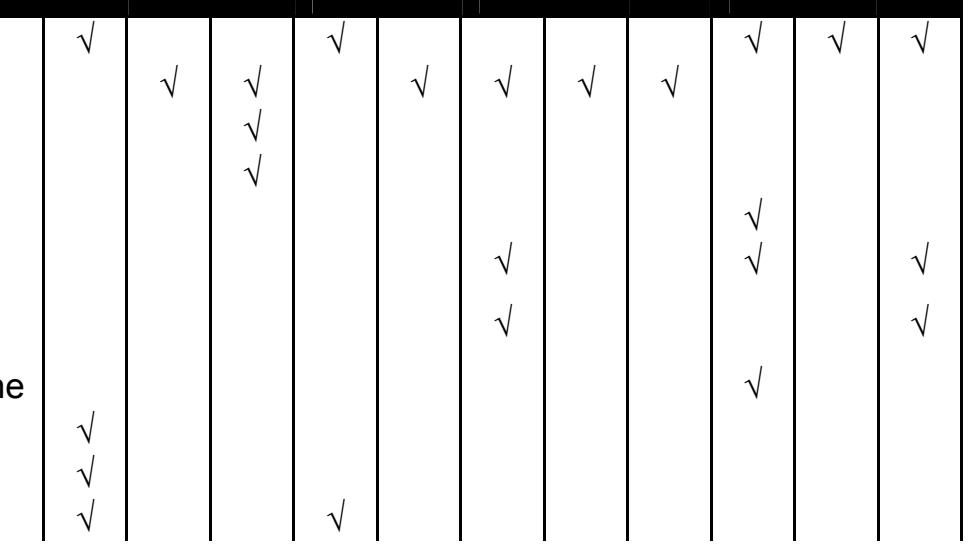


Table 2 - Contrasting the work on holistic models for capacity expansion (cont)

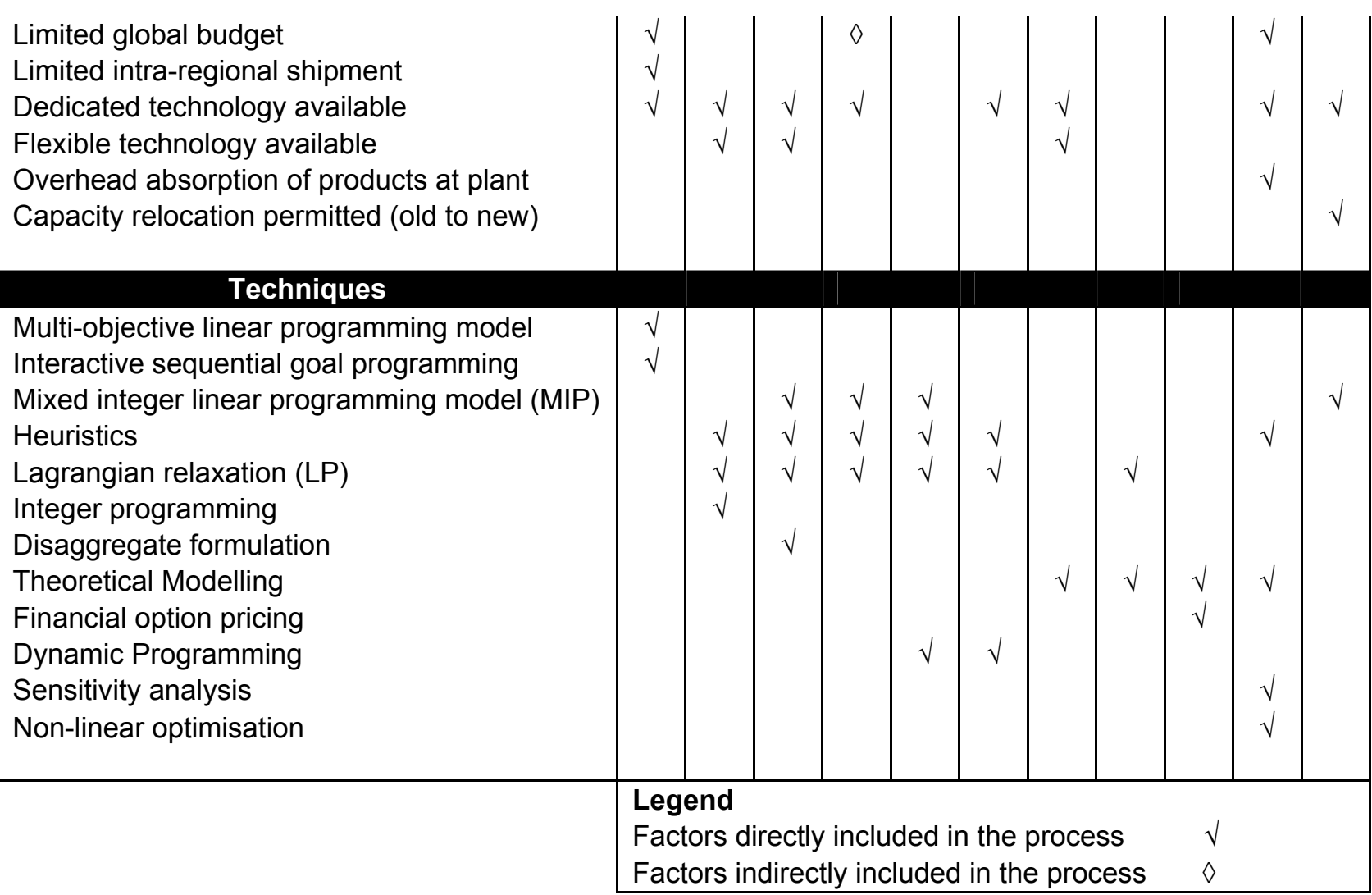

